\title{
Mother's Personal Care during Post Partum Period
}

\section{Doaa M, Kamilia R, Ahmed R, Randa M}

B.SC. Nursing science, Maternal \& Gynecological Nursing, Faculty of Nursing, Ain Shams University

\begin{abstract}
A descriptive study design was used to evaluate primiparas' mothers' self-care practices during postpartum period. Setting: The study was conducted at the postnatal departments at Ain Shams Maternity University Hospital. Sample size: The study was conducted on 665 primipara mothers during postnatal period. Sample type: Simple random sample technique was used to select the sample for the study. Tools: Three tools of data collections were used; a structured interview questionnaire, Likert scale and observational checklist. Results: Concerning post-natal self-care practices the study revealed that $90.6 \%$ from mothers were performing breast care correctly, $86.1 \%$ from mothers were performing perineal care correctly, 58.9\% from them had healthy nutrition and $70.3 \%$ weren't implementing follow up visits. Conclusion: The study revealed that, the majority of mothers were performing breast care correctly, majority of mothers were performing perineal care correctly, more than one third of mothers had unhealthy nutrition during post natal period, and nearly three fourth from mothers weren't implementing follow up visits. The study revealed majority of mothers had positive attitudes toward post natal self-care.

Recommendation: Conducting an educational program for mothers in Maternal and Child Health Centers and must be started during late pregnancy to inform mothers about routine self-care during postnatal period. Providing pamphlets and posters for primipara mothers to increase their awareness about post-partum self-care practice.
\end{abstract}

Key words: Self-care practices, primipara mothers, postpartum period.

\section{Introduction}

Postnatal period is a period beginning immediately after the birth of child and extending for about six weeks. Effective postnatal period is an important phase in the mother's life. Postnatal care is one of the most important maternal health care for not only prevention of impairment and disabilities but also reduction of maternal mortality (Simkhada, 2012).
Becoming a mother is an important stage in every woman's life. Most different period for women is their growth into parenthood is precisely this postpartum period. First time mothers in particular may feel anxious about how they are going to cope with looking after themselves and their newborn. The confinement period, generally initial 6 weeks is accepted to be a defenseless period for the primipara mothers and this period significant progressions of both 
hormonal and social beginning happen ceaselessly (Dutta, 2014).

Postpartum maternal self-care is a neglected aspect of women's healthcare. This neglect is evident in the limited national health objectives and data related to maternal health. Delivery of a new baby is one of the happiest times in woman's life. But it also presents both physical and emotional challenges (Senarath, 2014).

Mothers as well as baby's future depends upon the type of self care practices followed by the mother after delivery. Postnatal care includes a woman in her role as mother, forms the back bone of the family. In every society, there exit varying practices, customs, beliefs and values which may be healthy or unhealthy (Raman, 2013).

The self-care component includes behaviors first related primarily to the mind and then behavior related primarily to the body. Those related to mind include relationships, psychological health, relaxations spiritually and play. The body related behaviors as exercise sleep and dreams nutrition, sexuality, environmental health, and physical health Self-care elements during postpartum period include personal hygiene, perineal care, checking the funds, breast care, nutrition, post natal care (Rew, 2015).

The major purposes of postpartum and postnatal care are to maintain and promote the health of the woman and her baby. The new parents need support for parenting and its responsibilities. Thus, the conceptual framework for guidance on postpartum and postnatal care should place the woman and the baby at the centre of care provision (World Health Organization, 2015).

The job of postpartum nurse in the early postpartum period is to help the new mother to regain her pre-pregnant state without complications and to provide a solid knowledge base of care for the new mother and new infant. The desired outcome is that the mother feels confident about taking care of herself and her infant and be prepared to resume her normal role in the community. To achieve this, the nurse guides the new mother through the predictable physiologic, emotional, and social changes that occur after pregnancy and helps her to develop coping strategies. Also the nurse has a role in providing social support and facilitating maternal-fetal attachment in the postpartum period to improve postpartum maternal adaptation (Bitar, 2010).

\section{Significance of the study}

Post partum complications are responsible for maternal mortality rate (MMR) during post-partum period. Maternal mortality rate during puerperium is the annual number of female deaths per 100,000 live births from any cause related to or aggravated by post natal complications. Most post partum complications is considered preventable if post natal self-care is followed effectively, 216 women died worldwide from 100,000 women due to post partum complications. In Egypt 33 maternal death per 100,000death (WHO, 2015).

No previous study was conducted at Maternal \& gynecological Nursing department for assessing self care practices of primiparas mothers during post partum period. Therefore, primipara mothers don't have past experience about self care practices. Postpartum period covers transitional time for a woman, her newborn and her family. The needs of woman during this period have been ignored in both developing and developed countries. Many concerns need to be addressed such as personal hygiene, exercises, breast care, perineal care and nutrition.

\section{Aim of the study}

To evaluate primiparas' mothers self care practices during postpartum period. 


\section{Methodology}

\section{Research design:}

A descriptive study design was used.

\section{Subjects (sampling):}

Sample type: Simple random sample technique was used.

Sample size: It was calculated according to estimated statistics by year 2014/2015 that, the number of normal vaginal delivery at Ain Shames Maternity University Hospital was 6650, so the study sample was calculated as 665 cases (primipara) that represented $10 \%$ of total number of deliveries in the previous year.

\section{Criteria:}

○ Primipara mothers.

○ Normal vaginal delivery without complications to mother or fetus.

\section{Sample technique:}

Blinded tossing technique was used after recording all cases admitted to the postpartum unit in the register book; the researcher gave a number for each mother in a separate paper and put them in a box then she selected one of them consequently. This technique followed for daily data collection till the completion of the specified study sample number.

\section{Tools of data collection:}

Three types of tools were used for data collection these were a structured interview questionnaire sheet, Likert scale and observation checklist

\section{First tool:}

\section{Interview questionnaire sheet:}

Interview questioner sheet was designed by the researcher after reviewing the related current and previous literature named "Primiparas mothers' knowledge regarding self-care practices during postpartum period" it included two parts:

\section{Part (1):}

First part was designed to assess primipara mother's general characteristics as age, education and residence (from question No.1 to question No. 8).

\section{Part (2):}

Second part was designed to assess mother's knowledge regarding self-care practices during post-partum period as well as their miss concepts (from question No. 1 to 12 ).

Knowledge was scored as the following:

- Incorrect answer scored as one

- Correct answer scored as two

So, the total incorrect knowledge score ranged from 1-12, and the total correct knowledge score ranged from 13-24.

\section{Second tool:}

Likert scale to assess mothers' attitude regarding self-care during postpartum period:

Likert scale adopted from Rudman (2011) to assess mothers' attitude regarding self-care during post-partum period. Likert scale included 9 statements each statement was evaluated as agree, disagree and uncertain. Likert scale was scored as:

- $\quad$ Three degrees for agree

- $\quad$ Two degrees for uncertain

- One degree for disagree 
So, total Likert scale scores ranged from 1-27. Total disagree scored 1-9, while, uncertain scored 10-18 and total agree scored 19-27.

\section{Third tool:}

\section{Post-partum self-care Observ-ational} checklist:

Observational checklist was designed to assess mother self-care during post-partum period for the following activities (breast care- perineal care - nutrition during postpartum period -regular post natal visit schedule). Breast care checklist (13 steps), perineal care checklist (12 steps) and Postpartum visits schedule (3 visits) adopted from Fraser, (2003). Nutritional checklist (5questions) adopted from Berens, (2005) and assessed components of breakfast, lunch and dinner.
Observational checklist (breast care, perineal care and post-partum visits schedule) each item of the checklist was scored as:

- Two for correct practice.

- One for in correct practice.

So, total practices of breast care scores1-26, total incorrect practices of breast care scores 1-13, and total correct scores were 14- 26.Totalpractices of perineal care scores 1-24, total incorrect practices of perineal care scores 1-12, and total correct practices scores were 13-24. Total postpartum visits scores $1-6$, total incorrect visits scores 1-3 and total correct visits scores 4-6.

Nutritional assessment was scored as:

- Healthy

- Unhealthy 


\section{Results}

Table (1):Frequency distribution of the study sample according to general characteristics $(n=665)$

\begin{tabular}{|c|c|c|}
\hline General characteristics & No. & $\%$ \\
\hline \multicolumn{3}{|l|}{ Age by years } \\
\hline$<20$ & 33 & 4.9 \\
\hline $20-24$ & 391 & 58.8 \\
\hline $25-29$ & 200 & 30.1 \\
\hline$\geq 30$ & 41 & 6.2 \\
\hline Mean \pm SD & $24.0 \pm 3.2$ & \\
\hline \multicolumn{3}{|l|}{ Educational Status } \\
\hline Read and write & 9 & 1.4 \\
\hline Basic & 90 & 13.5 \\
\hline Intermediate & 483 & 72.6 \\
\hline University & 83 & 12.5 \\
\hline \multicolumn{3}{|l|}{ Marital Status } \\
\hline Married & 657 & 98.8 \\
\hline Widow & 6 & 0.9 \\
\hline Divorced & 2 & 0.3 \\
\hline \multicolumn{3}{|l|}{ Residence } \\
\hline Urban & 416 & 62.6 \\
\hline Rural & 249 & 37.4 \\
\hline \multicolumn{3}{|l|}{ Occupational Status } \\
\hline Employee & 91 & 13.7 \\
\hline Housewife & 574 & 86.3 \\
\hline \multicolumn{3}{|l|}{ Type of delivery } \\
\hline Normal without episiotomy & 25 & 3.8 \\
\hline Normal with episiotomy & 640 & 96.2 \\
\hline
\end{tabular}

Table (1) shows that, $58.8 \%$ of total sample their age ranged between $20-24$ years old. It was found that the mean age and SD of sample was $24 \pm 3.2$ years. Also it reveals that, $72.6 \%$ had intermediate education. In relation to mothers' marital status $98.8 \%$ were married. Concerning residence $62.6 \%$ of mothers were from urban area. In relation to occupation this table shows that, $86.3 \%$ were housewives. Finally this table shows that, $96.2 \%$ of the studied sample had normal delivery with episiotomy. 
Table (2):Frequency distribution of mothers' knowledge in relation to post-partum self-care $(n=665)$

\begin{tabular}{|c|c|c|c|c|}
\hline \multirow[t]{2}{*}{ Mothers' knowledge } & \multicolumn{2}{|c|}{ Correct } & \multicolumn{2}{|l|}{ Incorrect } \\
\hline & No. & $\%$ & No. & $\%$ \\
\hline Definition of post-partum self-care & 561 & 84.4 & 104 & 15.6 \\
\hline The components of post-partum self-care & 202 & 30.4 & 463 & 69.6 \\
\hline The aim of post-partum self-care & 649 & 97.6 & 16 & 2.4 \\
\hline Post-partum visits schedule & 226 & 34.0 & 439 & 66.0 \\
\hline The importance of healthy nutrition after birth & 649 & 97.6 & 16 & 2.4 \\
\hline The components of healthy nutrition after birth & 617 & 92.8 & 48 & 7.2 \\
\hline The practiced exercise after birth & 189 & 28.4 & 476 & 71.6 \\
\hline The enough rest after birth & 488 & 73.4 & 177 & 26.6 \\
\hline \multicolumn{5}{|l|}{ Duration of rest after birth } \\
\hline $3-4$ hours & 37 & 7.6 & 88 & 49.7 \\
\hline $5-6$ hours & 325 & 66.6 & 89 & 50.3 \\
\hline$>6$ hours & 126 & 25.8 & 0 & 0.0 \\
\hline The danger signs for mother after birth & 589 & 88.6 & 76 & 11.4 \\
\hline \multicolumn{5}{|l|}{ What are the danger signs } \\
\hline Incorrect & 307 & 52.1 & 76 & 100.0 \\
\hline Correct & 282 & 47.9 & 0 & 0.0 \\
\hline Starting sexual relation after birth & 636 & 95.6 & 29 & 4.4 \\
\hline
\end{tabular}

Table (2) reveals that, $84.4 \%$ from mothers had correct knowledge about the definition of post-partum self-care, also it shows that, $97.6 \%$ of mothers had correct knowledge about the aim of post-partum self-care, and at the same time $97.6 \%$ of them had correct knowledge about the importance of healthy nutrition after birth, also shows that, $92.8 \%$ had correct knowledge about components of healthy nutrition after birth, as well as $73.4 \%$ had enough rest after birth, and $88.6 \%$ had correct knowledge about danger signs after birth, also it shows that, $95.6 \%$ had correct knowledge about starting sexual relation after birth. This table also shows that, $69.6 \%$ of mothers had incorrect knowledge about components of post-partum self-care, also shows $66 \%$ had incorrect knowledge about post-partum visits, and $71.6 \%$ had incorrect knowledge about post-partum exercise. 
Table (3):Frequency distribution of post-partum primipara mothers' attitudes towards post-partum self$\operatorname{care}(\mathrm{n}=665)$

\begin{tabular}{|c|c|c|c|c|c|c|}
\hline \multirow[t]{2}{*}{ Mothers' attitudes } & \multicolumn{2}{|c|}{ Agree } & \multicolumn{2}{|c|}{ Uncertain } & \multicolumn{2}{|c|}{ Disagree } \\
\hline & No. & $\%$ & No. & $\%$ & No. & $\%$ \\
\hline Post-partum self-care is important & 658 & 98.9 & 4 & 0.6 & 3 & 0.5 \\
\hline $\begin{array}{l}\text { Post-partum self-care decreases complications for } \\
\text { mother }\end{array}$ & 652 & 98 & 6 & 0.9 & 7 & 1.1 \\
\hline Post-partum self-care enhances mother's health & 660 & 99.2 & 2 & 0.3 & 3 & 0.5 \\
\hline $\begin{array}{l}\text { Self-care helps in early detection of danger signs } \\
\text { to mother }\end{array}$ & 638 & 95.9 & 12 & 1.8 & 15 & 2.3 \\
\hline $\begin{array}{l}\text { Post-partum self-care has physical benefits for } \\
\text { mother }\end{array}$ & 630 & 94.7 & 13 & 2 & 22 & 3.3 \\
\hline $\begin{array}{l}\text { Post-partum self-care has psychological benefits } \\
\text { for mother }\end{array}$ & 622 & 93.5 & 17 & 2.6 & 26 & 3.9 \\
\hline Post-partum self-care is easy & 585 & 88 & 10 & 1.5 & 70 & 10.5 \\
\hline Post-partum self-care is inexpensive & 651 & 97.9 & 6 & 0.9 & 8 & 1.2 \\
\hline Post-partum self-care consumed reasonable time & 629 & 94.6 & 6 & 0.9 & 30 & 4.5 \\
\hline
\end{tabular}

Table (3) shows that, $98.9 \%$ from sample agreed that post-partum self-care was important, also it shows that, $98 \%$ agreed that post-partum self-care decreased from complications for mother, also it shows that, $99.2 \%$ from mothers agreed that postpartum self-care enhance mothers health, also it shows that, $95.9 \%$ from mothers agreed that self-care helped in early detection of danger signs of mother, also it shows that, $94.7 \%$ agreed that postpartum self-care had physical benefits for mother, also it shows that, $93.5 \%$ agreed that postpartum self-care had psychological benefits for mother, also it shows that, $88 \%$ agreed that postpartum self-care was easy, also it shows that, $97.9 \%$ agreed that postpartum self-care wasn't expensive, also it shows that, $94.6 \%$ agreed that postpartum self-care consumed reasonable time. 
Table (4):The association between total knowledge score and socio-demographic characteristics of the primipara mothers $(\mathrm{n}=665)$

\begin{tabular}{|c|c|c|c|}
\hline \multirow[t]{2}{*}{ Socio-demographic characteristics } & \multirow{2}{*}{$\frac{\text { Total knowledge score }}{(\text { mean } \pm \text { SD })}$} & \multicolumn{2}{|c|}{ ANOVA test } \\
\hline & & $\mathbf{F}$ & $\mathbf{P}$ \\
\hline \multicolumn{2}{|l|}{ Age (years) } & \multirow[t]{5}{*}{5.182} & \multirow[t]{5}{*}{$0.002 * *$} \\
\hline$<20$ & $15.2 \pm 0.6$ & & \\
\hline $20-24$ & $16 \pm 1.3$ & & \\
\hline $25-29$ & $16.2 \pm 1.4$ & & \\
\hline$>30$ & $15.9 \pm 1.5$ & & \\
\hline \multicolumn{2}{|l|}{ Educational status } & \multirow[t]{5}{*}{21.400} & \multirow[t]{5}{*}{$<0.001 * *$} \\
\hline Read/write & $15.0 \pm 1.0$ & & \\
\hline Basic & $15.3 \pm 0.9$ & & \\
\hline Intermediate & $16.0 \pm 1.4$ & & \\
\hline University & $16.8 \pm 1.2$ & & \\
\hline \multicolumn{2}{|l|}{ Marital status } & \multirow[t]{4}{*}{1.125} & \multirow[t]{4}{*}{0.325} \\
\hline Married & $15.9 \pm 1.4$ & & \\
\hline Widow & $15.2 \pm 0.4$ & & \\
\hline Divorced & $16.0 \pm 1.4$ & & \\
\hline Residence & & Student's t test & $\mathrm{P}$ \\
\hline Urban & $15.9 \pm 1.3$ & \multirow[t]{2}{*}{1.487} & \multirow[t]{2}{*}{0.137} \\
\hline Rural & $16.1 \pm 1.4$ & & \\
\hline \multicolumn{2}{|l|}{ Occupational status } & \multirow[t]{3}{*}{0.259} & \multirow[t]{3}{*}{0.796} \\
\hline Employee & $16 \pm 1.2$ & & \\
\hline Housewife & $15.9 \pm 1.4$ & & \\
\hline \multicolumn{2}{|l|}{ Delivery type } & \multirow[t]{3}{*}{3.400} & \multirow[t]{3}{*}{$<0.001 * *$} \\
\hline Normal without episiotomy & $16.9 \pm 1.3$ & & \\
\hline Normal with episiotomy & $15.9 \pm 1.3$ & & \\
\hline
\end{tabular}

Table (4) shows that, there was a highly significant difference between age ,education level, delivery type and knowledge ( $\mathrm{P}$ value $<0.001)$.

Table (5): Frequency distribution of primipara mothers' total self-care practices during postpartum period $(\mathrm{n}=665)$

\begin{tabular}{|l|c|c|c|c|c|}
\hline \multicolumn{1}{|c|}{ Items } & \multicolumn{2}{c|}{ Correct } & \multicolumn{2}{c|}{ Incorrect } \\
\hline \multicolumn{1}{|c|}{} & $\mathbf{n}$ & $\mathbf{\%}$ & $\mathbf{N}$ & \% \\
\hline Breast care & 603 & 90.6 & & 62 & 9.3 \\
\hline Perineal care & 573 & 86.1 & & 92 & 13.9 \\
\hline $\begin{array}{l}\text { Healthy nutrition (Meals contain all } \\
\text { component) }\end{array}$ & 392 & 58.9 & & 273 & 41.1 \\
\hline Post-partum follow up visits & 197 & 29.6 & & 468 & 70.3 \\
\hline
\end{tabular}

Table (5) shows that, mothers' total self-care practices during postpartum period were correctly done by the mothers as regards; breast care, perineal care, healthy nutrition and postpartum follow up visits $(90.6 \%, 86.1 \%, 58.9 \% \& 29.6 \%)$ respectively. 


\section{Discussion}

Concerning general chacteristics of the study subject; nearly two thirds of mothers had age ranged from $20-24$ years, the mean $\pm \mathrm{SD}$ age was $24.0 \pm 3.2$ and also nearly two thirds of mothers were from urban area, as well as near three fourth of mothers with intermediate education. While, majority of mothers were housewives and had normal delivery with episiotomy.

Concerning knowledge of studied mothers about post-partum self-care, the present study revealed that, nearly three fourth of mothers had incorrect knowledge about the components of post-partum selfcare, this might be due to lack of health education about post-partum period before the discharge from hospital. The previous study finding was in the same line with Lalitha, (2016) who assessed knowledge of (50) primipara mothers regarding self-care measures in postnatal unit in a selected maternity hospital and reported that, nearly three fourth of the primipara mothers had inadequate knowledge about self-care during postnatal period.

While, the previous study finding was contradicted with

Timilsina\&Dhakal(2015)who explored the knowledge regarding postnatal care among (196) postnatal mothers to find out the association of level of knowledge on postnatal care among postnatal mothers with their selected demographic variables in postnatal and gynecological ward of Western Regional Hospital and reported that, nearly two thirds of mothers had average knowledge about postnatal care.

The present study revealed that, about two thirds of mothers had incorrect knowledge about postnatal visits schedule. This might be due to lack of awareness about postnatal checkup as postnatal care is a neglected part in our society. The previous study finding was in the same line with
Adam, (2015) who assessed knowledge and practice of (150) mothers regarding self-care during puerperium in post natal ward in National Ribat University Hospital and reported that, more than half of mothers had incorrect knowledge about follow-up during post partum period.

While, the previous study finding was on the opposite side of Timilsina \& Dhakal, (2015) who explored the knowledge regarding postnatal care among (196) postnatal mothers to find out the association of level of knowledge on postnatal care among postnatal mothers with their selected demographic variables in postnatal and gynecological ward of Western Regional Hospital and mentioned that, nearly two thirds of mothers knew about postnatal checkup visits.

The result of the present study revealed that, the majority of mothers had correct knowledge about the components of healthy nutrition after birth. This result might be due to increased awareness about the importance of balanced nutrition and proper fluid intake during postnatal period to replace nutritional loss during delivery and to compensate with the lactation requirements. The previous study finding was in the same line with Fadel, (2009) who investigated (170) women about self-care during postpartum period in post natal unit in ElMansoura University Hospital and reported that, three fourth of the study sample had correct knowledge about elements of good nutrition.

Meanwhile, the previous study finding was disagreed with Lalitha, (2016) who assessed knowledge of (50) primipara mothers regarding self-care measures in postnatal unit in a selected maternity hospital and reported that, more than one fourth of mothers had incorrect knowledge about postnatal nutrition.

The result of the current study indicated that, nearly three fourth of mothers 
had incorrect knowledge about the practiced exercise after birth this may be due false beliefs and misconcepts about the importance of post-partum ambulation in our Arabic community. The previous study finding was in the same line with Fadel, (2009) who investigated (170) women about self-care during post-partum period in post natal unit in El-Mansoura University Hospital and reported that, more than three fourth of study sample had incorrect knowledge about postpartum exercise. Also the previous study finding was supported by Adam, (2015) who assessed knowledge and practice of (150) mothers regarding self-care during puerperium in post natal ward in National Ribat University Hospital and found that; the majority of mothers had incorrect knowledge about post natal exercise.

On the other hand the previous study finding was on contrary with Darling, (2014) who assessed knowledge and attitude of (100) post natal mothers regarding self-care after childbirth in selected maternity centers in Madurai and mentioned that, about three fourth of mothers had adequate knowledge about post-partum exercise.

The result of the present study revealed that, nearly three fourth of mothers had correct knowledge about enough rest after birth; this may be due to traditional believes about the importance of postnatal rest. The previous study finding was in agreement with Timilsina \& Dhakal, (2015) who explored the knowledge regarding postnatal care among (196) postnatal mothers to find out the association of level of knowledge on postnatal care among postnatal mothers with their selected demographic variables in postnatal and gynecological ward of Western Regional Hospital and reported that, near two thirds of mothers had correct knowledge about post natal rest.

Meanwhile, the previous study finding was disagreed with Abd El-Razek, (2013) who evaluated the teaching guideline enhancement of (200) mothers regarding self- care practice during the post-partum period at postnatal unit and outpatient clinics of obstetric department of El-Basher Hospital and found that, three fourth of mothers had incorrect knowledge about post natal rest and sleep.

The result of the current study revealed that, half of mothers had incorrect knowledge about post-partum danger signs for mother; this may be due to the primiparity of mothers and absence of previous experience. The previous study finding was supported with Adam, (2015) who assessed knowledge and practice of (150) mothers regarding self-care during puerperium in post-natal ward in National Ribat University Hospital and reported that, nearly three fourth of mothers had incorrect knowledge about post-partum maternal danger signs. Also the previous study finding was supported with Haila et al., (2010) who assessed knowledge about obstetric danger signs among pregnant women and stated that, the mothers' knowledge about postpartum danger signs was low.

Meanwhile, the previous study finding was disagreed with Timilsina \& Dhakal (2015) who explored the knowledge regarding postnatal care among (196) postnatal mothers to find out the association of level of knowledge on postnatal care among postnatal mothers with their selected demographic variables in postnatal and gynecological ward of Western Regional Hospital and mentioned that, the majority of mothers had correct knowledge about post natal maternal danger signs.

Regarding mothers' attitude towards post-partum self-care the result of the present study revealed that, the majority of mothers had positive attitudes towards post-partum self-care. The previous study finding was in the same line with Abd El-Razek, (2013) who evaluated the teaching guideline enhancement of (200) mothers about selfcare practice during the post-partum period at postnatal unit and outpatient clinics of 
obstetric department of El-Basher Hospital and reported that, the majority of the studied mothers had positive attitude towards postpartum self-care.

Meanwhile, the previous study finding was disagreed with Darling, etal. (2014) who assessed knowledge and attitude of (100) post natal mothers regarding self-care after childbirth in selected maternity centers in Madurai and mentioned that, the majority of postpartum mothers had negative attitudes towards self-care after childbirth.

Regarding primipara mothers' selfcare practices during postpartum period as regard breast care the present study revealed that, the majority of mothers did breast care correctly; this might be due to continuous providing of health education in hospital by health team about breast care. The previous study finding was in the same line with Darling, etal. (2014) who assessed knowledge and attitude of (100) post natal mothers regarding self care after childbirth in selected maternity centers in Madurai and reported that three fourth of mothers did breast care correctly.

Meanwhile, the previous study finding was on contrary with Adam, (2015) who assessed knowledge and practice of (150) mother regarding self-care during puerperium in the obstetric unit, post natal ward in National Ribat University Hospital and reported that, nearly three fourth of mothers practiced breast care incorrectly.

Concerning perineal care the result of the present study revealed that, two thirds of postpartum mothers didn't remove the solid pad from front to back; this might be due to lack of awareness about perineal care direction and the mothers were believing that "perineal care is part of ordinary personal hygiene and not need special care". The previous study finding was congruent with Fadel, (2009) who investigated (170) woman about self-care during post-partum period in post natal unit in El- Mansoura University
Hospital and reported that, more than two thirds of mothers didn't follow perineal cleanliness proper direction.

Regarding post-partum follow-up, the result of the current study showed that, two thirds of mothers didn't implement the third visit after birth this might be due to lack of awareness about postnatal checkup as postnatal care is a neglected part in our society. The previous study finding was in the same line with Lalitha, (2016): who assessed the knowledge of (50) primipara mothers regarding self-care measures in postnatal unit in a selected maternity hospital and reported that, the majority of mothers canceled the third postnatal visit.

Meanwhile, the previous study finding was in the opposite side of Timilsina \& Dhakal, (2015): who explored the knowledge regarding postnatal care among (196) postnatal mothers and to find out the association of level of knowledge on postnatal care among postnatal mothers with their selected demographic variables in postnatal and gynecological ward of Western Regional Hospital and reported that, nearly two thirds of mothers implemented the postpartum third visit.

The result of the present study revealed that, there was a highly statistical significant association between mothers' educational level and their knowledge regarding postpartum self-care; this may be due to woman with educational background had correct knowledge than mothers with limited educational background. The previous study finding was in the same line with Timilsina \& Dhakal, (2015) who explored the knowledge regarding postnatal care among (196) postnatal mothers to find out the association of level of knowledge on postnatal care among postnatal mothers with their selected demographic variables in postnatal and gynecological ward of Western Regional Hospital and reported that, there was a significant association between level of 
mothers' knowledge regarding postpartum self-care and education.

While, the previous study finding was in congruent with Bick et al., (2009) who investigated (100) African women for motherhood and reported that, education was important contributing factor to correct knowledge about self-care during postpartum with statistically significant association.

The result of the current study showed that, there was a highly statistical significant association between mother's age and knowledge regarding postpartum self-care; this result may be due to the mothers experience increased over time. The previous study finding was parallel to Lalitha, (2016) who assessed knowledge of (50) primipara mothers regarding self-care measures in postnatal unit in a selected maternity hospital and found that, a statistically significant association was observed between mothers' knowledge regarding postpartum self-care and age.

Meanwhile, the previous study finding was contrasted with Darling, etal. (2014) who assessed knowledge and attitude of (100) post natal mothers regarding self-care after childbirth in selected maternity centers in Madurai and mentioned that, there was no association between mothers' knowledge regarding postpartum self-care and their age.

On the other hand, the result of the current study revealed that, there was no correlation between mothers' knowledge and attitude regarding self-care during postpartum period. The previous study finding was incongruent with Darling, etal. (2014) who assessed knowledge and attitude of (100) post natal mothers regarding selfcare after childbirth in selected maternity centers in Madurai and reported that, a positive correlation between knowledge and attitude of postnatal mothers regarding selfcare after childbirth was found.
Recommendations

Based on the results of this study, the following recommend-ations were suggested:

- Conducting an educational program for mothers in $\mathrm{MCH}$ and must be started during late pregnancy to inform mothers about routine self-care during postnatal period.

- Providing pamphlets and posters for primipara mothers to increase their awareness about post-partum self-care practice.

\section{Further studies in this field:}

Barriers for performing self-care practices during post-partum period.

\section{References}

Abd El-Razek, A. (2013): Enhancement of mothers self-care practices for reliving minor discomfort during post-partum period, The Arab journal of the social sciences, Philadelphia, University Jordan, p55.

Adam, L.A. (2015): Assessment of knowledge and practice of mothers regarding self- care during puerperium, Ribat University p 22.

Berens, P. (2005): Overview of postpartum care. Up-to-date version 14.1.

Bick and Gichie, G.E. (2009): African woman preparation for motherhood. American Journal for maternal child nurses; 25(2): 86.

Bitar, S. (2010): Improving Health through Postpartum Home visits, Family Planning Counseling Scaling up Best Practices in Egypt, P165. 
Darling, B. Jiji \& Bazil, A.B.et al.(2014): Knowledge and attitude of post natal mothers regarding self-care after childbirth in selected maternity centers Journal of science (2014): Vol 4 /issue 1/ 40-44.

Dutta, D.C. (2014): Text book of obstetrics, Post-partum period $6^{\text {th }} \mathrm{ed}$, New central book agency, Kolkata, 3(5) 153-160.

Fadel, E.A. (2009): Self - care of women during postpartum period, thesis Submitted for partial fulfillment of the Requirement of Master Science in Nursing Degree in Maternity and Neonatal Health, p35-36.

Fraser \& Dian, M. (2003):Myles Text Book for Midwives, 40th ed., Churchill Living Stone Co., St. New York, (2) 101-120.

Haila, M., Gerbremarian, A. \& Alemseged, F. (2010): Knowledge about obstetric danger signs among pregnant women in Aletawondo district, sidama zone, Southern Ethiopia, Ethiop J Health Scie, 20(1), 25- 32.

Lalitha, H. (2016): A study to assess the knowledge on self care during post natal period among primipara mothers in a selected maternity hospital, International Journal of Applied Research, 2(4): 711712.
Raman Alamelu V. (2013): Traditional practices and nutritional taboos. The Nursing Journal of India, LXXIX (6), 46 -50 .

Rew, L. (2015): Adolescent health: A multidisciplinary approach to Theory, research and intervention, $5^{\text {th }}$ ed., Sage publication, USA, P128-129.

Rudman, A. (2011): Critical views on post partum care expressed by new mothers. International Journal of Nursing Studies; 32 (4): 478-479.

Senarath, U., Fernando, D.N., Vimpani, G. and Rodrigo, I. (2014): Factors associated with maternal knowledge of newborn care among hospital delivered mothers in Sri Lanka. Trop Med Hyg, 101 (8), 823.

Simkhada, B., Van Teijlingen, E. and Porter, M. (2012): Major problems and key issues in maternal health in Nepal. Medical J, 6, 258 -263. Theory, research and intervention, $5^{\text {th }}$ ed., Sage publication, U SA, P128-129.

Timilsina, S., Dhakal, R., et al. (2015): Saudi Journal of Medical and Pharmaceutical, SMEP, 1 (4)87-92.

WHO (2015): Technical consultation on postpartum and postnatal care, WHO Document Production Services, Geneva, p3 